\title{
The "Arab World" is not a useful concept when addressing challenges to public health, public health education, and research in the Middle East
}

\author{
lain Blair ${ }^{1}{ }^{*}$, Michal Grivna ${ }^{1}$ and Amer Ahmad Sharif ${ }^{2}$ \\ 1 Institute of Public Health, College of Medicine and Health Sciences, United Arab Emirates University, Al Ain, United Arab Emirates \\ ${ }^{2}$ Education Division, Dubai Healthcare City, Dubai, United Arab Emirates \\ *Correspondence: iain_blair@uaeu.ac.ae \\ Edited by: \\ Colette Joy Browning, Monash University, Australia \\ Reviewed by: \\ Himanshu Negandhi, Public Health Foundation of India, India \\ Nizar P. Farjou, Monash University, Australia
}

Keywords: public health, public health education, health research, Arab World

\section{INTRODUCTION}

Interest in public health in the "Arab World" has intensified following the political and social changes that have affected the Middle East since 2010. A new textbook has been published (1), an international meeting has been held (2), a network of experts has been formed, and a special edition of major medical journal has been published (3). But how useful is the "Arab World" as a way of defining a geographical region in order to focus attention on the health challenges that it faces and in particular the challenges relating to public health research and education. In this brief essay, the authors argue that its usefulness is limited because the countries of the Arab World, however defined, are too heterogeneous to allow meaningful communal debate of their problems and solutions. As an alternative it is recommended that countries in the region form smaller more homogenous issue-specific groupings to discuss common challenges and action.

\section{ARAB WORLD}

The preferred definition of the Arab World is the 22 member countries of the League of Arab States. The Eastern Mediterranean Region (EMR) of the World Health Organization (WHO) is a second important classification in which the Comoros, Mauritania, and Algeria are moved to the WHO Regional Office for Africa and three nonArab countries are added: Afghanistan, Iran, and Pakistan. In addition, South Sudan is included. A third widely used classification is the World Bank's Middle East and North Africa (MENA) grouping of 22 countries, which takes WHO EMR and excludes Sudan, Somalia, and Pakistan but adds Israel. Irrespective of which grouping is chosen, while there are "linguistic, political, historical, and socio-cultural links" between these nations there are also major dissimilarities at many levels and their heterogeneity is a major challenge (4). The region divides geographically into the Maghreb, the Mashreq, and the Gulf but the most important differences relate to levels of economic development, demography, population health status, inequity, political stability, history of conflict or war, presence of refugee or displaced populations, and health system organization. Given these differences does it make sense for countries to come together as the "Arab World" or WHO EMR to seek solutions to the specific challenges they face or would smaller issue-specific groups provide a more efficient forum for collaboration and joint action.

Attempts have already been made to define smaller more meaningful groups. On the basis of the World Bank income stratification, the Gulf States of Bahrain, Kuwait, Qatar, Saudi Arabia, United Arab Emirates, and Oman would be in a group of high income countries while Afghanistan, Comoros, Somalia, and South Sudan would be in a low income group while the remainder would be in a middle-income group. Furthermore, WHO already categorizes EMR countries into three groups based on health, health system performance, and expenditure on health (Table 1) and the Gulf States continue to work together through their health ministers' executive board (5).

\section{CHALLENGES}

The main challenges facing the countries of the region have been identified as inequities in health, rising exposure to health risks, increasing health care costs and unacceptably low levels of access to quality health care (6). To these may be added underinvestment in research for health and the need to reform public health education (2) and the continuing challenges faced by countries with complex emergencies (7).

In terms of exposure to health risk factors and disparities in health status, the countries of the region vary (Table 2). Yemen and Sudan have not fully passed through the epidemiological transition and have a different set of key health risk factors and so it is unhelpful to group them with the other nations. This also applies to other EMR Group 3 countries (Afghanistan, Djibouti, Pakistan, and Somalia) and Comoros and Mauritania. These countries generally have not yet passed through the demographic transition either. The most recent data show that under-five mortality (per 1000) was 98.5 in Afghanistan, 80.9 in Djibouti, 85.9 in Pakistan, 147.4 in Somalia, 104 in South Sudan, and 73.1 in Sudan while the total fertility rate (per women) in Afghanistan, Pakistan, Somalia, South Sudan, and Sudan was 5.1, 3.5, 6.4, 6.7, and 3.9 , respectively (8). However, with respect to risk factors and health status, 
Table 1 | WHO EMR country classification.

\begin{tabular}{|c|c|c|}
\hline Group 1 & Group 2 & Group 3 \\
\hline \multirow[t]{2}{*}{ Rapid social and economic development } & Middle-income countries & Low population health outcomes \\
\hline & & Lack of resources for health \\
\hline \multirow[t]{2}{*}{ High income } & Well-developed public health services & Political instability \\
\hline & Limited resources & Other complex development challenges \\
\hline Bahrain & Egypt & Afghanistan \\
\hline Kuwait & Islamic Republic of Iran & Djibouti \\
\hline Oman & Iraq & Pakistan \\
\hline Qatar & Jordan & Somalia \\
\hline Saudi Arabia & Lebanon & South Sudan \\
\hline \multirow[t]{5}{*}{ United Arab Emirates } & Libya & Sudan \\
\hline & Morocco & Yemen \\
\hline & Occupied Palestinian Territory & \\
\hline & Syrian Arab Republic & \\
\hline & Tunisia & \\
\hline
\end{tabular}

Source: World Health Organization Regional Office for the Eastern Mediterranean.

amongst the other nations there may be enough similarities to justify a regional grouping.

\section{DEMOGRAPHY, HEALTH SYSTEMS, AND COMPLEX EMERGENCIES}

However, the usefulness of a regional grouping is once more in doubt when demography and health systems are considered. The countries of EMR Group 1 which are also the countries of the Gulf Cooperation Council (GCC) have unique population structures with large expatriate populations relative to the size of their national populations. A typical population pyramid is that of the UAE where, 50\% of the population are non-citizen males of working age (9). This population structure along with rapid population growth from high net inward migration has necessitated high and increasing government spending on healthcare. Again, in the UAE, which is typical of other GCC countries, total expenditure on health (THE) has averaged between 2 and $4 \%$ of gross domestic product (GDP) over the past 15 years. Since UAE GDP has more than trebled in this time from $\$ 100$ billion to $\$ 380$ billion this means that THE has also increased from $\$ 752$ (per capita) in 2000 to $\$ 1640$ in 2011 . Of this, about $75 \%$ comes from government and the remaining 25\% from private sources namely insurance and outof-pocket payments. Government expenditure on health makes up about $9 \%$ of all government expenditure and has risen over fivefold from $\$ 1.7$ billion in 2000 to $\$ 9.5$ billion in 2011 easily outpacing both growth in population and GDP (11). In contrast, in EMR Group 2 countries, THE accounts for $6-8 \%$ of GDP, THE per capita is lower at $\$ 100-600$ and out-of-pocket expenditure makes up a higher proportion of THE (56\% in Lebanon, $58 \%$ in Egypt) (7). Jordan and Iraq are exceptions where although THE is low, only about a quarter is made up of out-of-pocket expenditure.

Health system strengthening is among the five strategic priorities identified by the WHO Regional Office for the Eastern Mediterranean for the next 5 years (along with progress on the Millenium Development Goals, action on non-communicable diseases, emergency preparedness, and emerging infectious diseases). Action to strengthen health systems inevitably translates to health system reform but because countries in the region face different issues, the solutions they seek are also different. In EMR Group 1 countries, health system reforms are designed to reduce government involvement in health and control expenditure by shifting payment and provision responsibilities to the private sector (12). In addition, in these countries there has been a rapidly growing private sector and this has demanded the development of new regulatory arrangements. On the other hand, EMR Group 2 countries have focused on universal coverage and reducing out-of-pocket health expenditure and risk of impoverishment from catastrophic medical expenses. The WHO EMR sub-divisions also have value when discussing the health consequences of war, conflict, and other complex emergencies, which tend to disproportionately affect Group 2 and Group 3 countries.

\section{NATIONAL HEALTH RESEARCH SYSTEMS}

Population health improvement and reducing health disparities require good evidence, which in turn requires good research. Popular metrics for assessing health research include government expenditure on research and development as a percentage of GDP, number of scientific publications, number of patents, and number of researchers per million population. Even if useful, often these metrics are not available, but this has not prevented commentators from being highly critical of health research in the Middle East. Ten countries in the region (Bahrain, Jordan, Kuwait, Lebanon, Oman, Qatar, Saudi Arabia, Tunisia, United Arab Emirates, and Yemen) participated in a mapping exercise in 2006 (13) using available metrics, qualitative data from stakeholder interviews and document analysis. The results revealed deficiencies in National Health Research Systems (NHRS) in the areas of capacity, activity, governance, priorities, strategy, outcomes, and use of research and there followed a plea for all countries 
Table 2 | Arab World/WHO EMR, life expectancy, GDP per capita, total expenditure on health, density of physicians, nurses and midwives, standardized mortality for selected conditions, main risk factors, selected countries, 2010.

\begin{tabular}{|c|c|c|c|c|c|c|c|c|}
\hline & & $\begin{array}{l}\text { United Arab } \\
\text { Emirates }\end{array}$ & Lebanon & Morocco & Egypt & Oman & Yemen & Sudan \\
\hline \multicolumn{2}{|c|}{$\begin{array}{l}\text { Life expectancy at birth, } 2010 \text {, } \\
\text { both sexes combined }\end{array}$} & 76.3 & 77.5 & 72.7 & 70.6 & 75.9 & 65.8 & 68.8 \\
\hline \multicolumn{2}{|l|}{ GDP per capita } & 49005 & 9904 & 3082 & 2801 & 25536 & 1617 & 1234 \\
\hline \multicolumn{2}{|c|}{$\begin{array}{l}\text { Per capita total expenditure on } \\
\text { health, US\$ }\end{array}$} & 1640 & 622 & 186 & 137 & 598 & 88 & 104 \\
\hline \multicolumn{2}{|c|}{ Physicians per 10,000 population } & 14.7 & 36.5 & 6.1 & 7.7 & 19.5 & 3.0 & 3.7 \\
\hline \multicolumn{2}{|c|}{$\begin{array}{l}\text { Nurses and midwives per } \\
10,000 \text { population }\end{array}$} & 26.0 & 29.1 & 9.0 & 13.8 & 19.5 & 7.2 & 10.0 \\
\hline \multirow{6}{*}{$\begin{array}{l}\text { Age- } \\
\text { standardized } \\
\text { death rate } \\
\text { (per } 100,000)\end{array}$} & All causes & 615 & 513 & 695 & 844 & 596 & 1068 & 799 \\
\hline & $\begin{array}{l}\text { Non- } \\
\text { communicable } \\
\text { diseases }\end{array}$ & 517 & 428 & 547 & 728 & 443 & 551 & 341 \\
\hline & $\begin{array}{l}\text { Cardiovascular } \\
\text { and circulatory } \\
\text { diseases }\end{array}$ & 295 & 248 & 239 & 441 & 241 & 331 & 132 \\
\hline & Neoplasms & 73 & 97 & 106 & 71 & 56 & 62 & 70 \\
\hline & Injuries & 52 & 47 & 30 & 35 & 70 & 47 & 85 \\
\hline & Diabetes & 34 & 18 & 84 & 12 & 66 & 27 & 20 \\
\hline
\end{tabular}

Sources: Institute for Health Metrics and Evaluation (10), WHO Regional Office for the Eastern Mediterranean Region (8).

to strengthen their NHRS but in different ways. A more recent report has further criticized health research in the region's countries although little new data was presented (14) while a further report from UAE presented a more optimistic view (15). But again it is not helpful to consider the region as homogenous whole with respect to health research. There is an obvious difference between EMR Group 1 countries which have the financial resources to carry out research but lack the higher education systems to generate new knowledge, EMR Group 2 countries which while not wealthy have mature education systems, good science and technology human resources, and good output of scientific publications and EMR Group 3 countries which have very limited financial and human resources for research (16). In addition, it is worth noting that EMR Group 1 countries score highly on metrics for innovation and use of information and communications technology. For example, the UAE is the highest-ranking Arab country in terms of its capacity for innovation and boasts the highest level of Internet availability. So once again attempting to diagnose problems and find solutions at the level of the Arab World is not helpful, a more sophisticated approach is required focusing on the needs of individual nations.

\section{HEALTH WORKFORCE AND PUBLIC HEALTH EDUCATION}

The availability, accessibility, and quality of the health workforce has rightly been identified as the bedrock on which a strong health system should be built (17) but few countries in the region have good data on their health workforce, they differ widely in terms of a key metric (density of skilled health professionals) (8) and have very different recruitment and development needs. For example, the UAE relies heavily on overseas recruitment to fulfill its health workforce needs and expatriates comprise $87 \%$ of physicians, $88 \%$ of dentists, $94 \%$ of allied health professionals, and $99 \%$ of 
midwives and nurses and there is a need for effective planning and training and retention strategies to guarantee a sustainable health workforce in the future (18). Commentators have described the public health workforce in the Arab World as "weak" while admitting that data is lacking (19). Kronfol in a recent historical review of health professions' education in the Arab world, while calling for improved training in public health and health services management, provides a more balanced view (20). He rightly shows that different countries face different problems and that solutions must be tailored to the needs of individual nations. This view is shared by Evashwick following a recent review of the extensive literature on the education of public health professionals. She comments that "relating public health education across national boundaries and education systems is complex given the diversity of public health education within a given country" (21). Countries in the region should conduct their own individual assessment of capacity within the public health workforce and design development programs to provide a sustainable and appropriate workforce for the future. Again as an example in the UAE, at the main public funded federal university, public health academics are already making changes to the nation's public health education framework at both undergraduate and postgraduate levels $(22,23)$.

This is our final example of where attempting to analyze and solve problems at the level of the Arab World is unhelpful. Workforce needs, availability of programs, accreditation, quality, and expenditure are challenges that different countries will face at different times. Identifying, analyzing, and solving these problems must be viewed as work in progress for each individual nation and attempting a universal solution at the level of the Arab World is inappropriate.

\section{CONCLUSION}

The Arab World is a disparate group of nations with very different health, public health, and health systems challenges. The idea that representatives of these nations can come together to debate and find common solutions has become fashionable recently but in reality this approach is unlikely to succeed. A more practical approach would be to analyze health problems and seek solutions at the level of smaller groups of similar nations that share common characteristics. The three WHO sub-divisions of EMR nations discussed in this paper or the GCC health ministers group are proposed as starting points.

Future meeting of these groups would have very different agendas. The high income countries of the Gulf would focus more on health systems reform, expenditure and quality, and less on universal coverage and out-of-pocket expenses. They would discuss the growing burden of obesity, diabetes, cardiovascular disease, and injury rather than polio elimination or under-five mortality. They would be more concerned with migrant and occupational health and less with the social determinants of health and the problems of conflict and displaced populations. Finally, they would be freed to consider health research needs, public health programs, health professions education, and workforce development.

At a time when there is an unprecedented vogue for attempting to find the solutions to health problems at a global or regional level it may be opportune to start to "think" as well as "act" a little closer to home.

\section{AUTHOR CONTRIBUTIONS}

All authors contributed to the ideas contained in this essay. Iain Blair produced the first draft. All authors refined the paper and edited the final version.

\section{REFERENCES}

1. Jabbour S, Giacaman R, Khawaja M, Nuwayhid I, editors. Public Health in the Arab World. Cambridge: Cambridge University Press (2012).

2. Council on Health Research for Development. Research for Health: Driving Equity and Development after the Arab Spring, Bellagio Conference Report. Geneva: Council on Health Research for Development (2013).

3. Horton R. Health in the Arab world: a renewed opportunity. Lancet (2014) 383(9914):283-284. doi:10.1016/S0140-6736(13)62703-8

4. Mandil A, Chaaya M, Saab D. Health status, epidemiological profile and prospects: Eastern Mediterranean Region. Int J Epidemiol (2013) 42(2):616-26. doi:10.1093/ije/dyt026

5. Koja TA, Hussein MS. Working Together for Better Health: Technical Cooperation among the GulfStates in the Field of Health through the Health Ministers' Council for Cooperation Council States. Riyadh: Executive Board for Health Ministers' Council for Cooperation Council States (2013).
6. World Health Organization Regional Office for the Eastern Mediterranean. Health Systems Strengthening in Countries of the Eastern Mediterranean Region: Challenges, Priorities and Options for Future Action. Cairo: Regional Committee for the Eastern Mediterranean Fifty-ninth session Provisional agenda item 3 EM/RC59/Tech.Disc.1 (2013).

7. Chan M. A Consistent Resolve can Improve Public Health Despite Crises. Address to the Regional Committee for the Eastern Mediterranean, Fifty-Seventh Session Cairo, Egypt 3 October 2010. Cairo: World Health Organization Regional Office for the Eastern Mediterranean (2010).

8. World Health Organization Regional Office for the Eastern Mediterranean. Demographic, Social and Health Indicators for Countries of the Eastern Mediterranean. Cairo (2013). Available at: http://applications.emro.who.int/dsaf/ EMROPUB_2013_EN_1537.pdf World Health Organization Regional Office for the Eastern Mediterranean

9. Blair I, Sharif AA. Population structure and the burden of disease in the United Arab Emirates. J Epidemiol Glob Health (2012) 2:61-71. doi:10. 1016/j.jegh.2012.04.002

10. The Global Burden of Disease Study. GBD Profile. Seattle: United Arab Emirates. Institute for Health Metrics and Evaluation (2010). Available at: http://www.healthmetricsandevaluation.org/sites/ default/files/country-profiles/GBD\%20Country\% 20Report\%20-\%20United\%20Arab\%20Emirates. pdf

11. World Health Organization. United Arab Emirates, National Expenditure on Health. Geneva (2013). Available at: http://apps.who.int/nha/database/ StandardReport.aspx?ID=REP_WEB_MINI_ TEMPLATE_WEB_VERSION\&COUNTRYKEY= 84041

12. Alkhamis A, Hassan A, Cosgrove P. Financing healthcare in Gulf Cooperation Council countries: a focus on Saudi Arabia. Int J Health Plann Mgmt (2013) 29:e64-82. doi:10.1002/hpm.2213

13. Kennedy A, Khoja TAM, Abou-Zeid AH, Ghannem $\mathrm{H}$, Ijsselmuiden C. National health research system mapping in 10 Eastern Mediterranean countries. East Mediterr Health J (2008) 14:502-17.

14. Ismail SA, McDonald A, Dubois E, Aljohani FG, Coutts AP, Majeed A, et al. Assessing the state of health research in the Eastern Mediterranean Region. J R Soc Med (2013) 106(6):224-33. doi:10. 1258/jrsm.2012.120240

15. Aw TC, Zoubeidi T, Al-Maskari F, Blair I. Challenges and strategies for quantitative and qualitative field research in the United Arab Emirates. Asian Pac J Cancer Prev (2011) 12(6):1641-5.

16. UNESCO. UNESCO Science Report 2010. Paris: UNESCO (2010).

17. Global Health Workforce Alliance. A Universal Truth: No Health Without a Workforce. Geneva: World Health Organization Avenue (2013).

18. World Health Organization. WHO Global Code of Practice on the international recruitment of health personnel [Internet]. Geneva (2013). Available at: http://www.who.int/hrh/migration/code/ practice/en/index.html

19. Jabbour S. Public health in the Arab World: at a crossroads. J Public Health Policy (2013) 34(2):356-60. doi:10.1057/jphp.2013.2 
20. Kronfol NM. Historical development of health professions' education in the Arab world: a review. East Mediterr Health J (2012) 18(11): 1157-65.

21. Evashwick CJ, Tao D, Bax K. Analysis of the literature pertaining to the education of public health professionals. Front Public Health (2013) 1:47. doi:10.3389/fpubh.2013.00047

22. Sharif AA, Blair I. Teaching about health systems in the UAE. Med Teach (2012) 34(2):176-7. doi:10.3109/0142159X.2012.644836

23. Blair I, Grivna M. Introduction of a New Modular Master of Public Health (MPH) programme in the United Arab Emirates. Paper presented at 1st Qatar
Medical Education Conference: improving quality of care through medical education. Doha (2012).

Conflict of Interest Statement: The authors declare that the research was conducted in the absence of any commercial or financial relationships that could be construed as a potential conflict of interest.

Received: 19 January 2014; paper pending published: 25 February 2014; accepted: 27 March 2014; published online: 09 April 2014.

Citation: Blair I, Grivna $M$ and Sharif AA (2014) The "Arab World" is not a useful concept when addressing challenges to public health, public health education, and research in the Middle East. Front. Public Health 2:30. doi: 10.3389/fpubh.2014.00030

This article was submitted to Public Health Education and Promotion, a section of the journal Frontiers in Public Health.

Copyright (c) 2014 Blair, Grivna and Sharif. This is an open-access article distributed under the terms of the Creative Commons Attribution License (CC BY). The use, distribution or reproduction in other forums is permitted, provided the original author(s) or licensor are credited and that the original publication in this journal is cited, in accordance with accepted academic practice. No use, distribution or reproduction is permitted which does not comply with these terms. 